\title{
Transcranial Magnetic Resonance-Guided Focused Ultrasound in X-Linked Dystonia-Parkinsonism
}

\author{
Roland Dominic G. Jamora ${ }^{1,2, * \mathbb{C}}$, Wei-Chieh Chang ${ }^{3,4}$ and Takaomi Taira $^{5}$ \\ 1 Division of Adult Neurology, Department of Neurosciences, College of Medicine and Philippine General \\ Hospital, University of the Philippines Manila, Manila 1000, Philippines \\ 2 Section of Neurology and Movement Disorder Service, Institute for Neurosciences, St. Luke's Medical Center, \\ Global City 1635, Philippines \\ 3 MR-Guided Focused Ultrasound Center, Chang Bing Show Chwan Memorial Hospital, \\ Changhua County 50529, Taiwan; changweichieh@gmail.com \\ 4 Department of Neurosurgery, Chang Bing Show Chwan Memorial Hospital, Changhua County 50529, Taiwan \\ 5 Department of Neurosurgery, Tokyo Women's Medical University, Tokyo 162-86666, Japan; ttaira@twmu.ac.jp \\ * Correspondence: rgjamora@up.edu.ph
}

Citation: Jamora, R.D.G.; Chang, W.-C.; Taira, T. Transcranial Magnetic Resonance-Guided Focused Ultrasound in X-Linked DystoniaParkinsonism. Life 2021, 11, 392. https://doi.org/10.3390/ life11050392

Academic Editors: Ryoma Morigaki and Ryosuke Miyamoto

Received: 9 April 2021

Accepted: 26 April 2021

Published: 26 April 2021

Publisher's Note: MDPI stays neutral with regard to jurisdictional claims in published maps and institutional affiliations.

Copyright: (c) 2021 by the authors. Licensee MDPI, Basel, Switzerland. This article is an open access article distributed under the terms and conditions of the Creative Commons Attribution (CC BY) license (https:/ / creativecommons.org/licenses/by/ $4.0 /)$.

\begin{abstract}
X-linked dystonia-parkinsonism (XDP) is a neurodegenerative condition found among males with maternal ancestry from Panay Island, Philippines. The treatment options are limited. We report on our experience of three XDP patients who underwent transcranial magnetic resonanceguided focused ultrasound (tcMRgFUS) pallidothalamic tractotomy. The three patients were all genetically confirmed XDP, with a mean XDP-Movement Disorder Society of the Philippines (MDSP) Scale score of $68.7 / 200$. All patients were on stable doses of their oral medications and their last botulinum toxin injection was 12 months prior to study. Two patients complained of moderate to severe arm pain 2-7 months after the procedure. There was an overall improvement in the XDPMDSP Scale score of $36.2 \%$ (18.7 vs. 15$)$ at 6 months and $30.1 \%$ (68.7 vs. 45.5$)$ at 1 year. Notably, there was worsening of the nonmotor subscale (part IIIB, nonbehavioral aspect) by $350 \%$ at 1 year. While these numbers are encouraging, there is a need to do a larger study on the safety and efficacy of tcMRgFUS on XDP.
\end{abstract}

Keywords: X-linked dystonia-parkinsonism; XDP; pallidothalamic tractotomy; transcranial magnetic resonance-guided focused ultrasound; XDP-MDSP Scale

\section{Introduction}

$\mathrm{X}$-linked dystonia-parkinsonism (XDP) is a disabling neurodegenerative condition with motor and nonmotor symptomatology [1,2]. The treatment of XDP has always been unsatisfactory compared to other movement disorders. The use of oral medications has never been absolutely effective [3,4]. Likewise, botulinum toxin is used but is limited by its duration of efficacy and cost $[5,6]$. The efficacy of pallidal deep brain stimulation (DBS) among XDP patients has been reported [7-9]. Recently, the use of magnetic resonance (MR)-guided focused ultrasound for XDP has been reported [10]. Thus, we aimed to report on our experience with transcranial MR-guided focused ultrasound (tcMRgFUS) pallidothalamic tractotomy in three XDP patients.

\section{Case Reports}

Case 1: A 31-year-old male with genetically confirmed XDP presented with a 2-year history of increased eyeblinking, followed by smaller handwriting. The following year, he experienced involuntary neck twisting. On examination, there was jaw opening dystonia, right torticollis, truncal hyperextension, flexion of the right toes, and left leg hip flexion when seated, and difficulty ambulating. He has moderate to severe dysarthria, mild masked facies, rigidity (neck and upper extremities, moderate bradykinesia, and gait difficulty). 
His baseline total XDP-Movement Disorder Society of the Philippines (MDSP) Scale score was 46/200 (I-13/44; II-20/76; IIIA-0/20; IIIB-1/20; IV-12/40) (see Table 1). His cranial MR imaging (MRI) showed symmetric linear signal abnormalities involving both lateral putaminal regions and mild bilateral caudate head atrophy. His medications were clonazepam $5 \mathrm{mg} /$ day, baclofen $30 \mathrm{mg} /$ day, and biperiden $6 \mathrm{mg} /$ day, with a reported relief of about $50 \%$. His last botulinum toxin (BoNT) injection was 12 months prior to the left pallidothalamic tractotomy.

Table 1. Summary of XDP-MDSP Scale scores before and after treatment with tcMRgFUS pallidothalamic tractotomy.

\begin{tabular}{|c|c|c|c|c|c|}
\hline XDP-MDSP Scale & Case 1 & Case 2 & Case 3 & Average & $\begin{array}{c}\text { \% Improvemen } \\
\text { Compared to } \\
\text { Baseline }\end{array}$ \\
\hline \multicolumn{6}{|l|}{ Baseline } \\
\hline I-Dystonia & 13 & 34 & 9 & 18.7 & \\
\hline II-Parkinsonism & 20 & 36 & 13 & 23 & \\
\hline IIIA-Behavioral & 0 & 3 & 0 & 3 & \\
\hline IIIB-Nonbehavioral & 1 & 15 & 3 & 1 & \\
\hline IV-Activities of daily living & 12 & 36 & 10 & 19.3 & \\
\hline Total & 46 & 124 & 36 & 68.7 & \\
\hline \multicolumn{6}{|l|}{1 week } \\
\hline I-Dystonia & 6 & 30 & 6 & 14 & 25.1 \\
\hline II-Parkinsonism & 14 & 26 & 13 & 17.7 & 23.0 \\
\hline IIIA-Behavioral & 0 & 1 & 0 & 0.3 & 90.0 \\
\hline IIIB-Nonbehavioral & 0 & 6 & 2 & 2.7 & -170.0 \\
\hline IV-Activities of daily living & 6 & 33 & 4 & 14.3 & 25.9 \\
\hline Total & 26 & 96 & 26 & 49.3 & 28.2 \\
\hline \multicolumn{6}{|l|}{1 month } \\
\hline I-Dystonia & 5 & 27 & 5 & 12.3 & 34.2 \\
\hline II-Parkinsonism & 15 & 29 & 13 & 19 & 17.4 \\
\hline IIIA-Behavioral & 0 & 1 & 0 & 0.3 & 90.0 \\
\hline IIIB-Nonbehavioral & 0 & 6 & 1 & 2.3 & -130.0 \\
\hline IV-Activities of daily living & 6 & 30 & 4 & 13.3 & 31.0 \\
\hline Total & 26 & 93 & 24 & 47.7 & 30.5 \\
\hline \multicolumn{6}{|l|}{6 months } \\
\hline I-Dystonia & 7 & 28 & 10 & 15 & 19.7 \\
\hline II-Parkinsonism & 19 & 23 & 7 & 13 & 43.5 \\
\hline IIIA-Behavioral & 0 & 1 & 0 & 0.3 & 89.0 \\
\hline IIIB-Nonbehavioral & 1 & 6 & 2 & 3 & -200.0 \\
\hline IV-Activities of daily living & 5 & 30 & 2 & 12.3 & 36.2 \\
\hline Total & 33 & 88 & 23 & 48 & 30.1 \\
\hline \multicolumn{6}{|l|}{9 months } \\
\hline I-Dystonia & 14 & 25 & NA & 26.5 & -41.7 \\
\hline II-Parkinsonism & 20 & 23 & NA & 21.5 & 6.5 \\
\hline IIIA-Behavioral & 0 & 1 & NA & 0.5 & 83.3 \\
\hline IIIB-Nonbehavioral & 3 & 6 & NA & 4.5 & -350.0 \\
\hline IV-Activities of daily living & 13 & 30 & NA & 21.5 & -11.4 \\
\hline Total & 50 & 85 & NA & 67.5 & 1.7 \\
\hline \multicolumn{6}{|l|}{12 months } \\
\hline I-Dystonia & 11 & NA & 10 & 10.5 & 43.8 \\
\hline II-Parkinsonism & 23 & NA & 7 & 15 & 34.7 \\
\hline IIIA-Behavioral & 1 & NA & 1 & 1 & 66.7 \\
\hline IIIB-Nonbehavioral & 4 & NA & 5 & 4.5 & -350.0 \\
\hline IV-Activities of daily living & 17 & NA & 10 & 13.5 & 30.0 \\
\hline Total & 56 & NA & 35 & 45.5 & 33.8 \\
\hline
\end{tabular}

NA: not available. 
Case 2: A 32-year-old male with genetically confirmed XDP presented with a 4-year history of frequent eye blinking and abdominal contractions, followed by left foot dorsiflexion. A year later, he developed truncal flexion and dysphagia. He eventually had to use a cane for ambulating, progressing to using a wheelchair. On examination, there was jaw opening dystonia, blepharospasm, laryngeal dystonia, left torticollis, flexion of the trunk, and left leg extension associated with difficulty in ambulating. He has mild dysarthria, rigidity (neck and all extremities), moderate to severe bradykinesia, and gait difficulty. His baseline total XDP-MDSP Scale score was 124/200 (I-34/44; II-36/76; IIIA-3/20; IIIB-15/20; IV-36/40) (see Table 1). His cranial MRI showed symmetric linear signal abnormalities involving both lateral putaminal regions and moderate bilateral caudate head atrophy. His medications were clonazepam $4 \mathrm{mg} /$ day and zolpidem $10 \mathrm{mg} /$ day, with a reported relief of about $60 \%$. His last botulinum toxin (BoNT) injection was 12 months prior to the right pallidothalamic tractotomy.

Case 3: A 38-year-old male with genetically confirmed XDP complained initially of eye sensitivity to bright lights for about 2 years. This was followed by involuntary mouth opening and pain on his right hand with stiffness on his left hand. On examination, it was found that he had jaw opening dystonia, left torticollis, and truncal flexion. He has mild masked facies, rigidity (neck and the left extremities), mild bradykinesia in the hands, and a slightly stooped posture. His baseline total XDP-MDSP Scale score was 36/200 (I-9/44; II-13/76; IIIA-0/20; IIIB-3/20; IV-10/40) (see Table 1). His cranial MRI showed bilateral symmetric linear signal abnormalities involving the lateral putaminal regions and mild bilateral caudate head atrophy. His medications were clonazepam, 6-8 mg/day, and biperiden, $8 \mathrm{mg} /$ day, with a reported relief of about $75 \%$. His last botulinum toxin (BoNT) injection was 12 months prior to the left pallidothalamic tractotomy.

All patients had neurocognitive and neuropsychiatric clearances prior to the procedure. All patients underwent tcMRgFUS pallidothalamic tractotomy at the Show Chwan Memorial Hospital in Changhuan, Taiwan. This was approved by the Institutional Review Board (SCMH IRB No. 1080201).

\section{Procedure}

Several papers have been published on the procedure for MRgFUS thermoablation [11-16]. The operations were performed in a 1.5T MRI system (GE Optima MR450, USA) using the ExAblate Neuro device (InSightec, Haifa, Israel). Additional care was taken in head immobilization by fixation as our patients have severe cervical dystonia.

The pallidothalamic tract (PTT) was chosen for tractotomy. It was located at the midcommissural line in the anteroposterior direction, $10.0 \mathrm{~mm}$ lateral to intercommissural line (ICL) in the mediolateral direction, $7.5 \mathrm{~mm}$ to the thalamo-ventricular border, and $1.5 \mathrm{~mm}$ below to the intercommissural line in the dorsoventral direction. The center of the PTT target was adjusted by about $3 \mathrm{~mm}$ lateral to the mamillo-thalamic tract (MTT) and superior and medial to the medial subthalamic nucleus. The second target was $1 \mathrm{~mm}$ posterior, superior, and lateral to the first target.

The average in-table operation time was $176.8 \pm 40.6 \mathrm{~min}$ (range, 134-240 $\mathrm{min})$. The mean maximum energy reached 30,750.25 \pm 6246.06 J (range, 20,096-35,731 J) with a mean maximum temperature of $58.8 \pm 3.1{ }^{\circ} \mathrm{C}$ (range, $54-62{ }^{\circ} \mathrm{C}$ ). The temperature was also monitored in the MTT during sonications. Figure 1 shows the PTT lesion in Case 2, taken one day after the operation. 


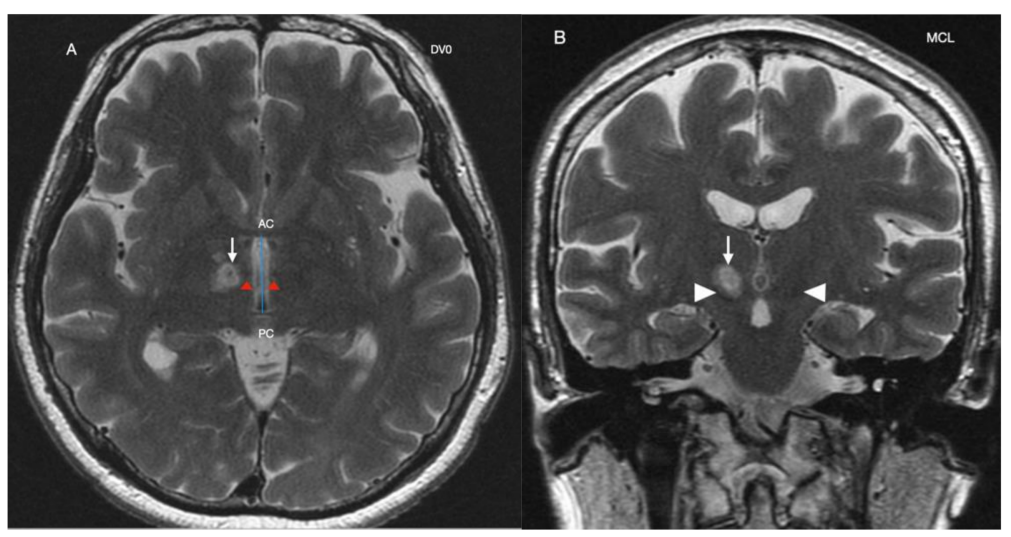

Figure 1. Cranial MRI of Case 2 at day 1 post-pallidothalamic tractotomy. (A): Axial cuts at DV0 showing the right pallidothalamic tract target lesion (white arrow) on postoperative day 1 . The intercommissural line (blue line) is the distance between the anterior commissure (AC) and the posterior commissure (PC). Red arrows point to the mamillo-thalamic tract. (B): Sagittal scan at midcommissural line (MCL). White arrow is target lesion. Arrow heads are the subthalamic nuclei.

The patients were awake and responsive during the whole procedures with full physiologic monitoring. They were examined by movement disorder neurologists for treatment effects and adverse events after each sonication. The operations were completed with the improvement of dystonia symptoms, as assessed by the neurologists.

Case 2 experienced claustrophobia and propofol $1 \%, 10 \mathrm{mg} / \mathrm{mL}$, was intravenously injected at $0.005 \mathrm{mg} / \mathrm{kg} / \mathrm{min}$ intermittently. The patient was awakened after each sonication. The rest of the patients were not given any sedative agents during the procedures. The patients' hospitalization was 10 days for preoperative planning and monitoring for complications before they flew back to Manila, Philippines.

Two months after the procedure, Case 1 started experiencing right arm pain, with a Visual Analogue Scale Score (VAS) of 6-8/10, which was persistent and occasionally relieved with tramadol. For Case 3, he also started to complain of right arm pain, with a VAS $8 / 10$ at 7 months after the procedure, partially relieved by tramadol.

There was an overall improvement in the XDP-MDSP Scale score of $30.1 \%$ (68.7 vs. 48 ) at 6 months and $33.8 \%$ (68.7 vs. 45.5 ) at 1 year (see Table 1). It should be noted that the 9-month and 12-month follow ups were lacking data from a patient. Looking at the individual subscales, at the 6th month of observation, there was an improvement in part I (dystonia) of $19.7 \%$ (18.7 vs. 15), part II (parkinsonism) of $43.5 \%$ (23 vs. 13), part IIIA (behavioral nonmotor) of $89 \%$ (3 vs. 0.3), and part IV (activities of daily living) of $36.2 \%$ (19.3 vs. 12.3). However, there was worsening of the part IIIB (nonbehavioral nonmotor) by $200 \%$ ( 1 vs. 3 ). The dystonia and activities of daily living scores at 9 months follow up were noted to have worsened.

At 12-month follow up, the improvement was likewise seen in all subscales: $43.8 \%$ (18.7 vs. 10.5 ) for part I, $34.7 \%$ ( 23 vs. 15 ) for part II, $66.7 \%$ ( 3 vs. 1 ), and for part IV, $30 \%$ (19.3 vs. 13.5), except for part IIIB. At this time, the worsening noted for part IIIB was at $-350 \%$ (1 vs. 4.5$)$.

\section{Discussion}

The management of XDP is still very limited. There are no effective oral medications available $[3,4]$. Chemodenervation with botulinum toxin helps but is limited by the cost $[5,6]$. Pallidal DBS seems to be the best option as of now, with very significant improvement of the dystonia and a variable response of the parkinsonism symptoms [7-9]. However, not everyone can undergo DBS due to its cost [6] and possibly due to its invasive nature.

One possible option is the use of tcMRgFUS. This has been approved for other movement disorders such as essential tremors and Parkinson's disease (PD) [16,17]. It has 
also been used in a patient with musician's dystonia [18]. An abstract on the use of tcMRgFUS for XDP is available [10]. Moreover, a clinical trial is underway looking on the efficacy of tcMRgFUS (Vim thalamus or the globus pallidus interna) in patients with treatment-refractory symptoms of movement disorders (essential tremors, Holme's tremor, PD, dystonia, Wilson's disease, Huntington's disease, tardive dyskinesias, and orofacial dyskinesia) (ClinicalTrials.gov Identifier: NCT02252380).

Our patients had tcMRgFUS pallidothalamic tractotomy. The globus pallidus internus is connected to the ventroanterior and ventrolateral parts of the thalamus by the PTT [11]. A lesion in the PTT improves the dystonia by interrupting the cortico-basal ganglia-thalamocortical circuit through the modulation of the pallidal efferents to the thalamus [11,19].

However, unlike other reports on pain relief, two of our patients experienced severe pain over their right arm months after the procedure. The pain can be described as a central pain syndrome, which usually results from damage to any structure along the spino-thalamo-cortical pathways that convey pain and temperature information and is associated with abnormal inhibitory regulation of the posterior thalamus by the zona incerta [20]. Maldaptive plasticity, brought about by the changes in the connections due to the pallidothalamic tractotomy might cause the pain [20].

This pain contributed to the marked worsening ( $-350 \%$ at 12 months) seen in part IIIB of the XDP-MDSP Scale that contributed to the smaller overall improvement seen in our patients. Had the traditional scales (Burke-Fahn-Marsden Dystonia Rating Scale (BFMDRS) and the Unified Parkinson Disease Rating Scale (UPDRS)) been used, we would not have been able to account for these nonmotor symptoms. These nonmotor symptoms are an important determinant of quality of life and disability in movement disorder patients [2] The XDP-MDSP Scale was developed for XDP patients, using existing scales, including the BFMDRS and UPDRS as the "gold standards" [21]. Moreover, the XDP-MDSP Scale has a subscale on nonmotor features (behavioral and nonbehavioral aspects, parts IIIA and IIIB, respectively) and activities of daily living (part IV).

Among patients who had DBS (range of follow up: 6-84 months), the reported improvement in the dystonia (using the BFMDRS) was between 3 and 100\%, with worsening of the scores in some patients (7-21\%). For the parkinsonian symptoms, using the UPDRS, the improvement was lower at 5-81\%, with worsening in some patients of up to $121 \%$ [7]. While these DBS results cannot be directly compared with the tcMRgFUS results as a different scale was used, regarding the XDP-MDSP Scale, we can see that in both instances there was an overall improvement in the dystonia and, for a smaller percentage, the parkinsonism. The 12-month data are encouraging, with improvements noted in the different subscales (dystonia, parkinsonism, behavioral nonmotor, and activities of daily living) except for the nonbehavioral nonmotor part (sleep disturbance, pain and other sensations, bladder incontinence, fatigue, saliva and drooling). The biggest improvement was seen in the behavioral nonmotor part (cognition, apathy, anxiety, depression, and irritability and aggression) at $66.7 \%$, followed by dystonia ( $43.8 \%$ ), and parkinsonism (34.7\%). Indeed, this proved that the nonmotor aspects of the disease are important [2].

One advantage of the tcMRgFUS is its noninvasive approach [19]. This also removes the need for repeated patient follow up for DBS programming. We also need to take note of some complications noted with tcMRgFUS thalamotomy, such as sensory and gait disturbance [22]. An inherent limitation of the procedure is its unilaterality. There are no reports on staged campotomy for other types of dystonia, unlike in PD, dystonic camptocormia, and Meige's syndrome [22-25]. Another factor to consider is the progression of the disease itself. Unfortunately, we do not have any data on the rate of progression of XDP as well as how it will affect the parkinsonism phase of the disease. Despite these limitations, these cases showed that tcMRgFUS may improve the patient's XDPMDSP score, except for the nonbehavioral symptoms at 1-year follow up. There is a need to conduct a controlled study on the long-term safety and efficacy of tcMRgFUS pallidothalamic tractotomy in XDP patients. 
Author Contributions: Conceptualization, R.D.G.J., W.-C.C. and T.T.; methodology, R.D.G.J., W.C.C. and T.T.; formal analysis, R.D.G.J., W.-C.C. and T.T.; data curation, R.D.G.J., W.-C.C. and T.T.; writing-original draft preparation, R.D.G.J.; writing-review and editing, R.D.G.J., W.-C.C. and T.T.; supervision, R.D.G.J.; project administration, R.D.G.J., W.-C.C. and T.T.; funding acquisition, W.-C.C. All authors have read and agreed to the published version of the manuscript.

Funding: This research was funded by Min-Ho Huang, President of the Show Chwan Memorial Hospital.

Institutional Review Board Statement: The study was conducted according to the guidelines of the Declaration of Helsinki and was approved by the Institutional Review Board of Show Chwan Memorial Hospital, Changhuan, Taiwan (SCMH IRB No. 1080201, 27 February 2019).

Informed Consent Statement: Informed consent was obtained from all subjects involved in the study.

Data Availability Statement: The data presented in this study are available on request from the corresponding author.

Acknowledgments: We thank Min-Ho Huang, President of Show Chwan Memorial Hospital for the financial support, and Hui-Gin Lai, Kun-Hong Li, and Wei Lin for their assistance. We also thank Christine Klein and her team at the University of Lübeck, Germany, for the genetic testing of our patients. We also thank Estrela Silverio of the Movement Disorders Service of St. Luke's Medical Center, Quezon City, Philippines and Anthony Piano of The Medical City for their assistance.

Conflicts of Interest: Wei-Chieh Chang has received lecture fees from Insightec. The rest of the authors declare no conflict of interest. The funder had no role in the design of the study; in the collection, analyses, or interpretation of data; in the writing of the manuscript, or in the decision to publish the results.

\section{References}

1. Lee, L.V.; Rivera, C.; Teleg, R.A.; Dantes, M.B.; Pasco, P.M.; Jamora, R.D.; Arancillo, J.; Villareal-Jordan, R.F.; Rosales, R.L.; Demaisip, C.; et al. The unique phenomenology of sex-linked dystonia parkinsonism (XDP, DYT3, "Lubag"). Int. J. Neurosci. 2011, 121, 3-11. [CrossRef] [PubMed]

2. Jamora, R.D.; Ledesma, L.K.; Domingo, A.R.; Cenina, A.R.; Lee, L.V. Nonmotor features in sex-linked dystonia-parkinsonism (XDP, DYT3). Neurodegener. Dis. Manag. 2014, 4, 283-289. [CrossRef] [PubMed]

3. Jamora, R.D.; Diesta, C.C.; Pasco, P.M.; Lee, L.V. Oral pharmacological treatment of X-linked dystonia parkinsonism: Successes and failures. Int. J. Neurosci. 2011, 121, 18-21. [CrossRef] [PubMed]

4. Jamora, R.D.; Teleg, R.A.; Cordero, C.P.; Villareal-Jordan, R.F.; Lee, L.V.; Pasco, P.M. Levodopa+carbidopa in X-linked dystonia parkinsonism (XDP/DYT3/Lubag): A randomized, double-blind, placebo-controlled trial. Acta Med. Philipp. 2018, 52, 510-514. [CrossRef]

5. $\quad$ Rosales, R.L.; Ng, A.R.; Santos, M.M.; Fernandez, H.H. The broadening application of chemodenervation in X-linked dystoniaparkinsonism (part II): An open-label experience with botulinum toxin-A (Dysport ${ }^{\circledR}$ ) injections for oromandibular, lingual, and truncal-axial dystonias. Int. J. Neurosci. 2011, 121, 44-56. [CrossRef]

6. De Roxas, R.C.; Jamora, R.D. Cost-analysis of the different treatment modalities in X-linked dystonia-parkinsonism. Front. Neurol. 2019, 10, 500. [CrossRef]

7. Abejero, J.E.; Jamora, R.D.; Vesagas, T.S.; Teleg, R.A.; Rosales, R.L.; Anlacan, J.P.; Velasquez, M.S.; Aguilar, J.A. Long term outcomes of pallidal deep brain stimulation in X-linked dystonia parkinsonism (XDP): Up to 84 months follow up and review of literature. Parkinsonism Relat. Disord. 2019, 60, 81-86. [CrossRef]

8. Kilbane, C.; Witt, J.; Galifianakis, N.B.; Glass, G.A.; Volz, M.; Heath, S.; Starr, P.A.; Ostrem, J.L. Long-term outcomes of bilateral pallidal deep brain stimulation for X-linked dystonia and parkinsonism. Stereotact. Funct. Neurosurg. 2018, 96, 320-326. [CrossRef]

9. Brüggemann, N.; Domingo, A.; Rasche, D.; Moll, C.K.; Rosales, R.L.; Jamora, R.D.; Hanssen, H.; Münchau, A.; Graf, J.; Weissbach, A.; et al. Association of pallidal neurostimulation and outcome predictors with X-linked dystonia-parkinsonism. JAMA Neurol. 2019, 76, 211-216. [CrossRef]

10. Chang, W.; Taira, T.; Jamora, R.D.; Chiu, P.; Lin, W. First experience with MR-guided focused ultrasound in the treatment of X-linked dystonia-parkinsonism (XDP). Mov. Disord. 2019, 34. Available online: https://www.mdsabstracts.org/abstract/ first-experience-with-mr-guided-focused-ultrasound-in-the-treatment-of-x-linked-dystonia-parkinsonism-xdp/ (accessed on 1 April 2021).

11. Horisawa, S.; Fukui, A.; Tanaka, Y.; Wendong, L.; Yamahata, H.; Kawamata, T.; Taira, T. Pallidothalamic tractotomy (Forel's Field H1-tomy) for dystonia: Preliminary results. World Neurosurg. 2019, 129, e851-e856. [CrossRef]

12. Gallay, M.N.; Moser, D.; Federau, C.; Jeanmonod, D. Anatomical and technical reappraisal of the pallidothalamic tractotomy with the incisionless transcranial MR-guided focused ultrasound. A technical note. Front. Surg. 2019, 6, 2. [CrossRef]

13. Meng, Y.; Huang, Y.; Solomon, B.; Hynynen, K.; Scantlebury, N.; Schwartz, M.L.; Lipsman, N. MRI-guided focused ultrasound thalamotomy for patients with. medically-refractory essential tremor. J. Vis. Exp. 2017, 130, 56365. [CrossRef] 
14. Ghanouni, P.; Pauly, K.B.; Elias, W.J.; Henderson, J.; Sheehan, J.; Monteith, S.; Wintermark, M. Transcranial MRI-guided focused ultrasound: A review of the technologic and neurologic applications. AJR Am. J. Roentgenol. 2015, 205, 150-159. [CrossRef]

15. Magara, A.; Bühler, R.; Moser, D.; Kowalski, M.; Pourtehrani, P.; Jeanmonod, D. First experience with MR-guided focused ultrasound in the treatment of Parkinson's disease. J. Ther. Ultrasound. 2014, 2, 11. [CrossRef]

16. Bond, A.E.; Shah, B.B.; Huss, D.S.; Dallapiazza, R.F.; Warren, A.; Harrison, M.B.; Sperling, S.A.; Wang, X.Q.; Gwinn, R.; Witt, J.; et al. Safety and efficacy of focused ultrasound thalamotomy for patients with medication-refractory, tremor-dominant Parkinson disease a randomized clinical trial. JAMA Neurol. 2017, 74, 1412-1418. [CrossRef]

17. Elias, W.J.; Lipsman, N.; Ondo, W.G.; Ghanouni, P.; Kim, Y.G.; Lee, W.; Schwartz, M.; Hynynen, K.; Lozano, A.M.; Shah, B.B.; et al. A randomized trial of focused ultrasound thalamotomy for essential tremor. N. Engl. J. Med. 2016, 375, 730-739. [CrossRef]

18. Horisawa, S.; Yamaguchi, T.; Abe, K.; Hori, H.; Sumi, M.; Konishi, Y.; Taira, T. A single case of MRI-guided focused ultrasound ventro-oral thalamotomy for musician's dystonia. J. Neurosurg. 2018, 131, 384-386. [CrossRef]

19. Krishna, V.; Sammartino, F.; Rezai, A. A review of the current therapies, challenges, and future directions of transcranial focused ultrasound technology advances in diagnosis and treatment. JAMA Neurol. 2018, 75, 246-254. [CrossRef]

20. Masri, R.; Quiton, R.I.; Lucas, J.M.; Murray, P.D.; Thompson, S.M.; Keller, A. Zona incerta: A role in central pain. J. Neurophysiol. 2009, 102, 181-191. [CrossRef]

21. Pasco, P.M.; Jamora, R.D.; Rosales, R.L.; Diesta, C.C.; Ng, A.R.; Teleg, R.A.; Go, C.L.; Lee, L.; Fernandez, H.H. Validation of the XDP-MDSP rating scale for the evaluation of patients with X-linked dystonia-parkinsonism. NPJ Park. Dis. 2017, 3, 24. [CrossRef]

22. Godinho, F.; Magnin, M.; Filho, P.T.; Reis, P.; Moraes, O.; Nascimento, M.; Costa, C.; de Oliveira, M.O.; Rocha, M.S. Stereotactic lesion in the Forel's Field H: A 2-years prospective open-label study on motor and nonmotor symptoms, neuropsychological functions, and quality of life in Parkinson disease. Neurosurgery 2019, 85, E650-E659. [CrossRef]

23. Franzini, A.; Levi, V.; Franzini, A.; Dones, I.; Messina, G. Staged pallidotomy: MRI and clinical follow-up in status dystonicus. Br. J. Neurosurg. 2019, 33, 184-187. [CrossRef]

24. Gallay, M.N.; Moser, D.; Magara, A.E.; Haufler, F.; Jeanmonod, D. Bilateral MR-guided focused ultrasound pallidothalamic tractotomy for Parkinson's disease with 1-year follow up. Front. Neurol. 2021, 12, 601153. [CrossRef] [PubMed]

25. Eisenberg, H.M.; Krishna, V.; Elias, W.J.; Cosgrove, G.R.; Gandhi, D.; Aldrich, C.E.; Fishman, P.S. MR-guided focused ultrasound pallidotomy for Parkinson's disease: Safety and feasibility. J. Neurosurg. 2020, 27, 1-7. [CrossRef] [PubMed] 